\title{
Hydrological Impacts of the Grand Ethiopian Renaissance Dam (GERD) on River Nile Hydrology Within Sudan
}

\author{
Mansour Ahmed Mordos ${ }^{1}$, El Sadig Abdellah Sharfi ${ }^{2}$, Bouran Awadh Mohammed ${ }^{3}$, \\ Kevin Wheeler ${ }^{4}$ \\ ${ }^{1}$ Water and Reservoir Directorate, Merowe Dam, Merowe, Sudan \\ ${ }^{2}$ Department of Civil Engineering, University of Khartoum, Khartoum, Sudan \\ ${ }^{3}$ Department of Civil Engineering, University of Khartoum, Faculty of Engineering, Khartoum, Sudan \\ ${ }^{4}$ Environmental Change Institute, University of Oxford, Oxford, UK
}

\section{Email address:}

mordos76@yahoo.com (M. A. Mordos), elsadigsharfi@gmail.com (El S. A. Sharfi), bouranawad@rocketmail.com (B. A. Mohammed), kevin.wheeler@ouce.ox.ac.uk (K. Wheeler)

\section{To cite this article:}

Mansour Ahmed Mordos, El Sadig Abdellah Sharfi, Bouran Awadh Mohammed, Kevin Wheeler. Hydrological Impacts of the Grand Ethiopian Renaissance Dam (GERD) on River Nile Hydrology Within Sudan. Hydrology. Vol. 8, No. 3, 2020, pp. 41-51.

doi: $10.11648 /$ j.hyd.20200803.12

Received: April 11, 2020; Accepted: September 1, 2020; Published: September 19, 2020

\begin{abstract}
This paper aims to quantify the potential impacts of the Grand Ethiopian Renaissance Dam (GERD) on the River Nile System within Sudan territories, in the context of hydrology. GERD reservoir with a capacity of $\left(74 \mathrm{Km}^{3}\right)$ is approximately 1.5 times the mean annual flow of the Blue Nile, which contributes by $57 \%$ of the River Nile runoff. According to Ethiopian proposal, the GERD is going to be filled to the full supply level of $640 \mathrm{~m}$ a.m.s.1 in 6 to 7 years. The first filling of GERD reservoir was planned to be in 2014 , but it is postponed until the writing of this report. However, it's most likely to be started this year 2020. Consequently, significant impacts are highly anticipated during this first filling period, and all over the long-term operation. Definitely, this will change the Blue and Main Nile hydrological regime. In order to achieve the research objectives, a daily time step Rule Based Simulation model has been developed using River Ware Software (University of Colorado) representing the entire River Nile system within Sudan. Three scenarios were adopted, baseline (Hydrological System without GERD), GERD first filling and long-term operation. River inflows, water levels, run-off and hydrograph shapes within Sudan water system were investigated and compared to the average baselines, taking into consideration the recent Dams' operation policies and rules. In addition, a simple-approach operation scenario was adopted for GERD. Likewise, as hydrological inputs, 30 years of historical time series were used. Given the above, the hydrological impacts in six representative River Nile reaches within Sudan were estimated, then highlighted and judiciously investigated. In summary, it could be concluded that, during the first filling of GERD, the runoff of the Blue Nile will decrease by $30 \%$. While, for the Long Run, significant changes are expected for to the Blue Nile hydrograph, resulting in slight to moderate changes for the Main Nile Hydrograph. It's expected that the impacts of GERD on River Nile hydrology will lead to increasing average discharges during summer period by a range of $10-500 \%$ for different months and hydrology, on the other hand, reducing flood peak by approximately $10-25 \%$. In the long run, Water Levels in different reaches are expected to vary by \pm ( 2 to 3 ) meters. It's concluded that operation policies of the existing Sudanese dams will no longer be valid for the new Situation after GERD, further studies are highly recommended to be conducted.
\end{abstract}

Keywords: GERD, River Nile, Hydrological Impacts, River Ware, Hydrograph, Water Level, Run-Off

\section{Introduction}

\subsection{Background}

The construction of the Grand Renaissance Ethiopian Dam (GERD) started in 2011 on Blue Nile. According to Ethiopia and due to current work progress, the impounding water in the reservoir most likely will be starting in July 2018, to be filled by the end of 2023 . The storage capacity of the dam is $74 \mathrm{~km}^{3}$, which is about 1.5 times the mean annual flow of the Blue Nile at the site $\left(48 \mathrm{~km}^{3}\right)$ [1]. The consequences are expected to cause significant impacts downstream. It is agreed that the GERD will completely change the flow 
regime of the Blue Nile. The Blue Nile floods are going to be reduced, while base flow will increase [2]. Accordingly, the Main River Nile will be influenced by these drastic changes in hydrology, subsequently.

\subsection{Impacts of Dams on Downstream}

Approximately two-thirds of the largest rivers in the world have some kind of damming along their courses that has several negative impacts, the less visible of which being hydrologic alteration through the controlled release of water from reservoirs [3]. Largely relying on data from twenty-one US rivers with alluvial beds and monumented cross sections, many semiarid, shows that dams consistently reduced flood peaks but had more variable effects on other elements of the flow regime [4].

Downstream effects of dams lead to a number of environmental and socioeconomic risks and, therefore, should be thoroughly examined in specific contexts [5]. Over the years, fluctuations in the flow of the Blue Nile have contributed to change the mean annual discharge by plus or minus 20 percent, with very severe consequences for water management in Egypt, Ethiopia and Sudan [6].

Claudia and others [7] stated that several authors have attempted to assess the impact of the finalised upstream Chinese dams. The Singaporean authors $\mathrm{Lu}$ and others [8] investigated the impact of the Manwan dam on downstream water levels at the Chiang Saen and Chiang Khong stations (time series from the 1960s up to 2006), the gauge stations nearest to the Chinese dams. They concluded that both hydrological regimes were influenced by the operation of the Manwan dam, with impacts being more evident in the dry season than in the wet season. It was found that the dam led to a reduction in low water levels and discharge, while high water level alterations were insignificant. This result contradicts the hopes of downstream nations with regard to inter-annual flow regulation (but one has to consider that part of the time span investigated by Lu et al. 2008 included the filling-up period) as well as the findings of Chapman and He [9]. They suspected (much earlier, and without scientific evidence) that the impact of the smaller Manwan and Dachaoshan dams would be insignificant and that changes would be noted only after the completion of the much larger Xiaowan dam.

Shokhrukh-Mirzo estimated for Rogan hydropower plant project (RHPP) in Tajikistan when it's operating in full electricity generation mode, that will yield a decrease of the Amudarya River annual discharge to downstream Uzbekistan in the summer irrigation period by $18 \%$ and an increase of the discharge in the winter time by $54 \%$. He added also during the irrigation period from April to September Uzbekistan will have less water, and in the rest of the year, from September to April, Uzbekistan may experience water abundance, which may lead to flooding [10].

\subsection{Problem Statement}

The GERD will be the largest dam ever constructed in the Blue Nile Basin with a reservoir of 74 Billion $\mathrm{m}^{3}$, [11]. It worth mentioning that, the Blue Nile, is the main tributary of the Nile, and the source of about $80 \%$ of the water during flood season (July - October) [2].

First impounding and long-term operation of GERD dam will generate downstream impacts related to water resources uses and management in Sudan and Egypt. GERD impounding completion and its downstream impacts on Sudan will significantly depend on the hydrological conditions in which impounding stage will occur. [11].

No doubt that the GERD is going to regulate Blue Nile and change its hydrological regime, which will affect the regime of the River Nile accordingly [12]. The research questions arise to emphasize on the changes on the River Reaches as below:

I. What are the expected changes in River flow rates?

II. What are the anticipated changes in water levels?

III. what is the potential effects on the seasonal and annual run-off?

IV. What are the anticipated changes in hydrograph shapes at different reaches?

\subsection{Objectives}

This research is seeking to quantify the potential impacts of GERD on Blue Nile and Main Nile hydrology regarding discharges, water levels, run-off and hydrograph shapes within Sudan. The impacts will be studied during first filling and for the long-term Operation of GERD.

\subsection{Nile Hydrology}

\subsubsection{River Nile Sources}

The Sources of the Nile are:

a. Ethiopia Highlands: source of Blue Nile, Atbara and Sobat Rivers

b. Equatorial Lakes: source of Bahr EL Jebel

c. Bahr El Ghazal Basin (Sudan): source of Bahr El Ghazal Rivers

\subsubsection{River Nile Annual Yield}

The annual discharge of the Nile varies from $154 \mathrm{Km}^{3}$ (1978/79) to $42 \mathrm{Km}^{3}(1913 / 14)$ [2]. The average annual flow for the period (1905-55) is estimated at $84 \mathrm{Km}^{3}$, measured at Aswan equivalent to $93 \mathrm{Km}^{3}$ at Sinnar (Central Sudan). [2].

\subsection{GERD General Information}

The GERD project site is located on the Abbaye/Blue Nile River (Figure 1), approximately $20 \mathrm{~km}$ upstream of the Sudanese Ethiopian borders [11].

The GERD is a Roller Compacted Concrete (RCC) dam with a dam height of 145 meters, complemented by a saddle dam about $5 \mathrm{~km}$ long and about 50 meters high. [11].

The scheme, from the entrance of its reservoir at Sibra Abbay Mesopotamia to the dam site, extends over a corridor approximately $246 \mathrm{~km}$. The reservoir area will cover 1,874 square kilometers at full supply level (FSL) of 640 meters above sea level a.m.s.l. [11].

The total storage volume is $74 \mathrm{Km}^{3}$ with an active storage volume of $59.2 \mathrm{Km}^{3}$. For a design flow of 4,305 cubic meters 
per second and a maximum net head of 133 meters and plant factor of 0.31 , the expected average energy production per year is $15,692 \mathrm{GWH}$, with installed capacity of up to 6000 MW [11]. The plant has two surface powerhouses equipped with sixteen power generating units and a switchyard. The installed power is flexible (base or peak) and the plant has been designed so that the installed capacity may be built in several stages. [11].

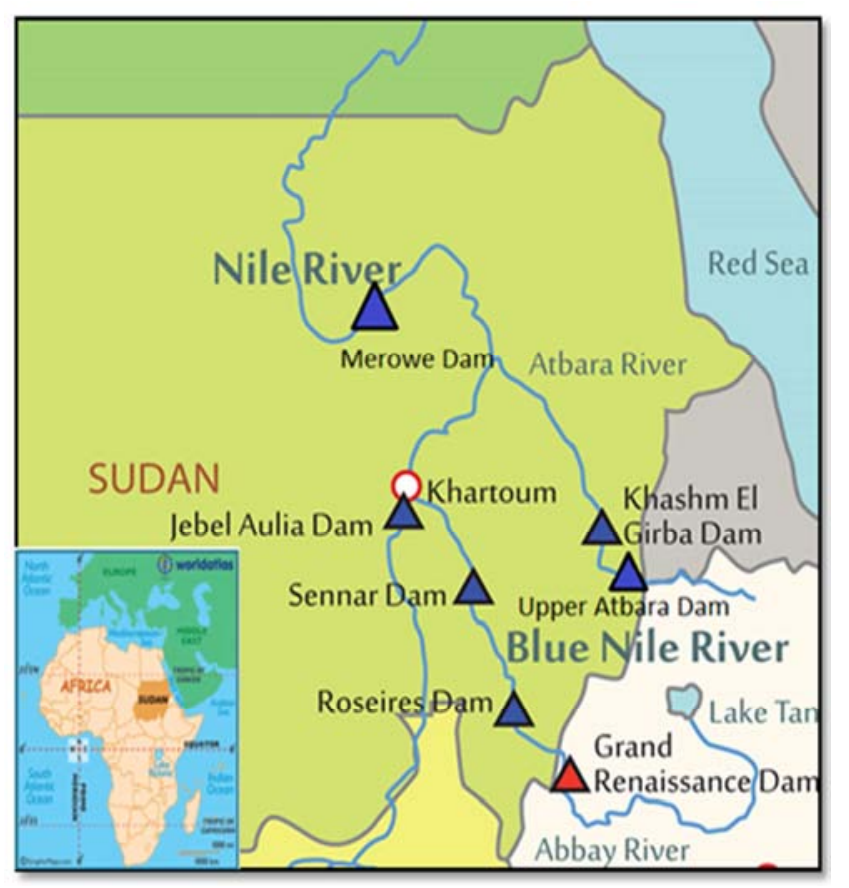

Figure 1. Location of GERD and Sudan Dams [13].

\section{Methodology}

The downstream impacts of GERD in the context of hydrology within Sudan have been investigated using a water resources system model for calculating the anticipated changes in hydrological regime. The investigated area extends from GERD Dam down to Dongola town, some 313 $\mathrm{Km}$ downstream Merowe dam. The powerful River Ware software for river basin modeling from University of Colorado has been utilized to perform the study.

\subsection{Nile River Basin Model Development}

River Ware is a river system modeling tool. It is an ideal platform for operational decision-making, responsive forecasting [14], operational policy evaluation, system optimization, water accounting, water rights administration, water quality modeling and long-term resource planning. The wide range of applications is made possible by a choice of computational time steps ranging from 1 hour to 1 year [14].

A comprehensive model has been built to simulate the hydrologic processes of reservoirs, river reaches, diversions, distribution canals, consumptive uses, and hydropower generation for all River Nile system in Sudan.

The Model has been constructed with 1 day time step resolution, and calibrated using detailed information including historical hydrologic flow data, operation policies, and decision matrix which control and manage the whole water system in Sudan.

Simulation runs were performed for one scenario of GERD filling, extracting 30 years of the daily time series for the period from 1963 to 2010 as hydrology inputs for the simulation period from 2017 - 2046, adopting Index Sequential Method in order to generate artificial stochastic inputs for the first filling runs. However, a simple approach and obvious assumptions were used.

\subsection{Hydrology Inputs}

For the first filling, as a usual modeling techniques, 30 years of historical observed stream flows were taken and synthesized an ensemble of flow data for 30 traces to represent different hydrology cases.

Each single trace data set for hydrology were used as inputs for single model run elapsing years 2018 to 2048 with the same sequence, and repeat this procedure for the 30 runs sequentially. The general trend and changes of the hydrological regime in the system during GERD filling were easily observed.

Alternatively, and particularly for the long-term operation, simple approach used as a determine case which had generated determine results that could be simply interpreted, then traced, without complicity. Historical data for the 30 years were used for all inflows inputs in the long-term model.., accordingly, trends and changes after GERD were easily concluded.

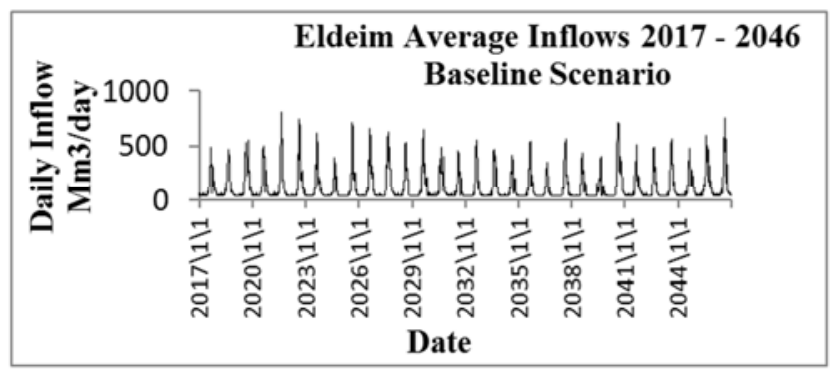

Figure 2. 30 years inflow Hydrograph at Eldeim Station Before GERD.

\subsection{Dams Operation Policy and Rules}

The operation policy of the entire system were prepared in Rule Set, in order to simulate the system dynamics. The recent rule curves for Sudan dams were adopted and used during simulation. Existing operation policies for all reservoirs were used with and without consideration of the GERD. However, as an example for operation guide curve, figures 3 explains the average operating guide curves for Roseires dam. Operation rules for other dams including Merowe, Sennar, Jebel Aulia, Khashm Elgirba and Upper Atbara were configured in the same manner as Roseires Dam. 


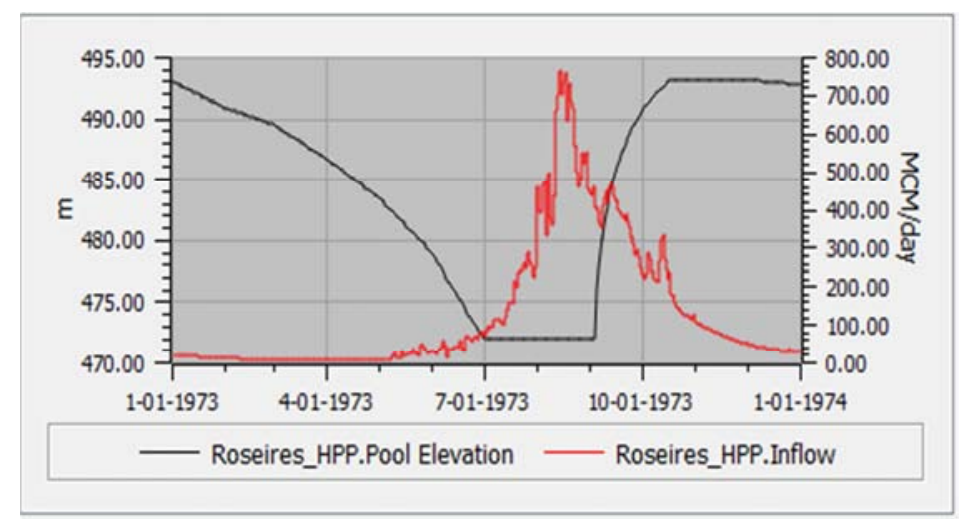

Figure 3. Annual Operation Guide Curves for Roseries Dam.

\subsection{Model Topology and Set-up}

Sudan water Resources Model has been developed for the entire country. The model covers the area between Eldeim gauge station at the Ethiopia-Sudan boarders down to Dongola.

The hydrological network was identified and located representing the natural flow direction from upstream at southern direction towards downstream at the northern direction. Main and lateral river reaches, confluences and reservoirs were located and identified. Moreover, an assessment for the system losses and gain (Evaporation, Rainfalls) and infiltration were done. It worth mentioning that source point for hydrology inputs and key stations were declared and determined. Rating curves (Stage - Discharge Curve) were developed for all key stations from Eldeim to Dongola. The model time step was set to one day (daily) and the simulation period is 6 years for the initial filling scenario and 24 years for the long term operation scenario. Thus, the total horizon of the simulation was 30 years represented the period from 2017 up to 2046.

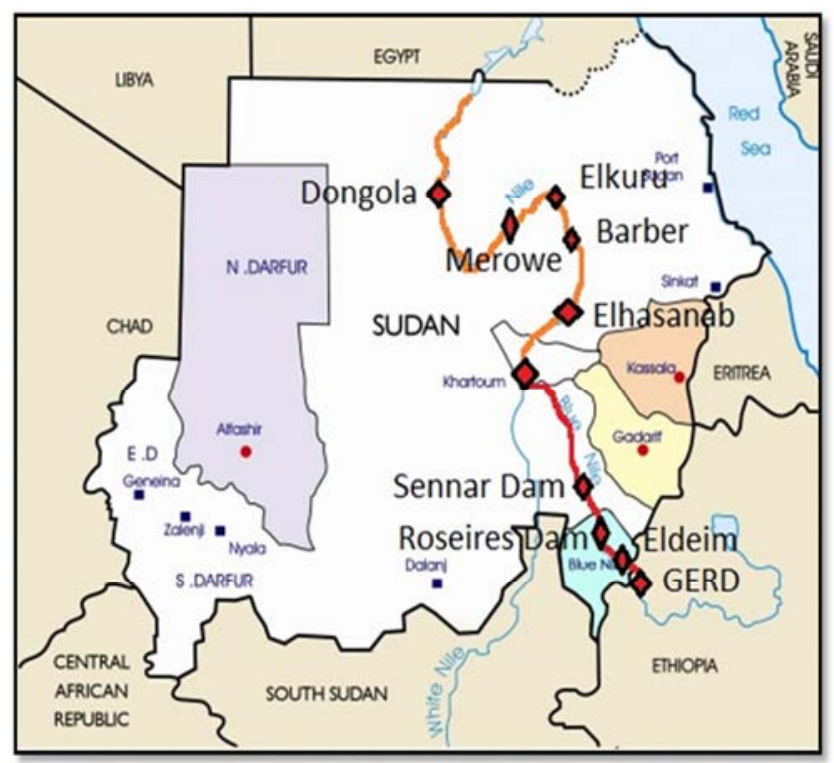

Figure 4. Sudan Simulated River Reaches from Eldeim to Dongola (Sudan National Survey Authority).
Model topology and layout was schematically sketched up and built using RiverWare software, with specialized tools to locate system features (River Reaches, Gauge Stations, Pump stations, Dam, reservoirs, Confluence, and etc..). Successive and/or dependent objects in the system were connected together in the model similarly to the reality.

The consequent step was setting-up of the model, in which the readily prepared inflows and water levels time series were faded to the model, precisely matching the time elapse for the model. In addition to time series, dams and reservoirs characteristics and hydropower plants properties were added also. Initial and boundary condition were set, and constrains were identified. Most of the hydraulic data and information were populated to the model in this stage including evaporation losses, rainfalls, water uses and demands. All these meta data were checked, revised and verified before used in the model. At this point, the model could be numerically simulated, and obtaining results, but were not close to the reality, some calibration efforts were needed.

\subsection{Model Calibration and Validation}

The objective of the calibration simulation was to identify and validate the physical losses, and lag time in the system. The calibration solution of the model utilized available data to replicate historical conditions and validate the simulation. Historical elevation data was available for Roseries, Sennar and Merowe Reservoirs, in addition to direct outflow data. The simulated results were compared against the observed time series for the year 2010. The model assumptions regarding the losses and transmission times were manually adjust by try and error until best fitting were obtained for whole model.

\subsection{Simulation of First Impounding of GERD Reservoir}

GERD first filling scenario is very crucial, because it, directly, affects the hydrology of Blue Nile which affects the hydrological regime of the main Nile (Figure 4) [12].

Although, the first filling is expected to start in 2018 [1], no agreement has been confirmed to the time of this paper. However, the real scenario might differ slightly from the proposed plan for filling considered for the model run. 

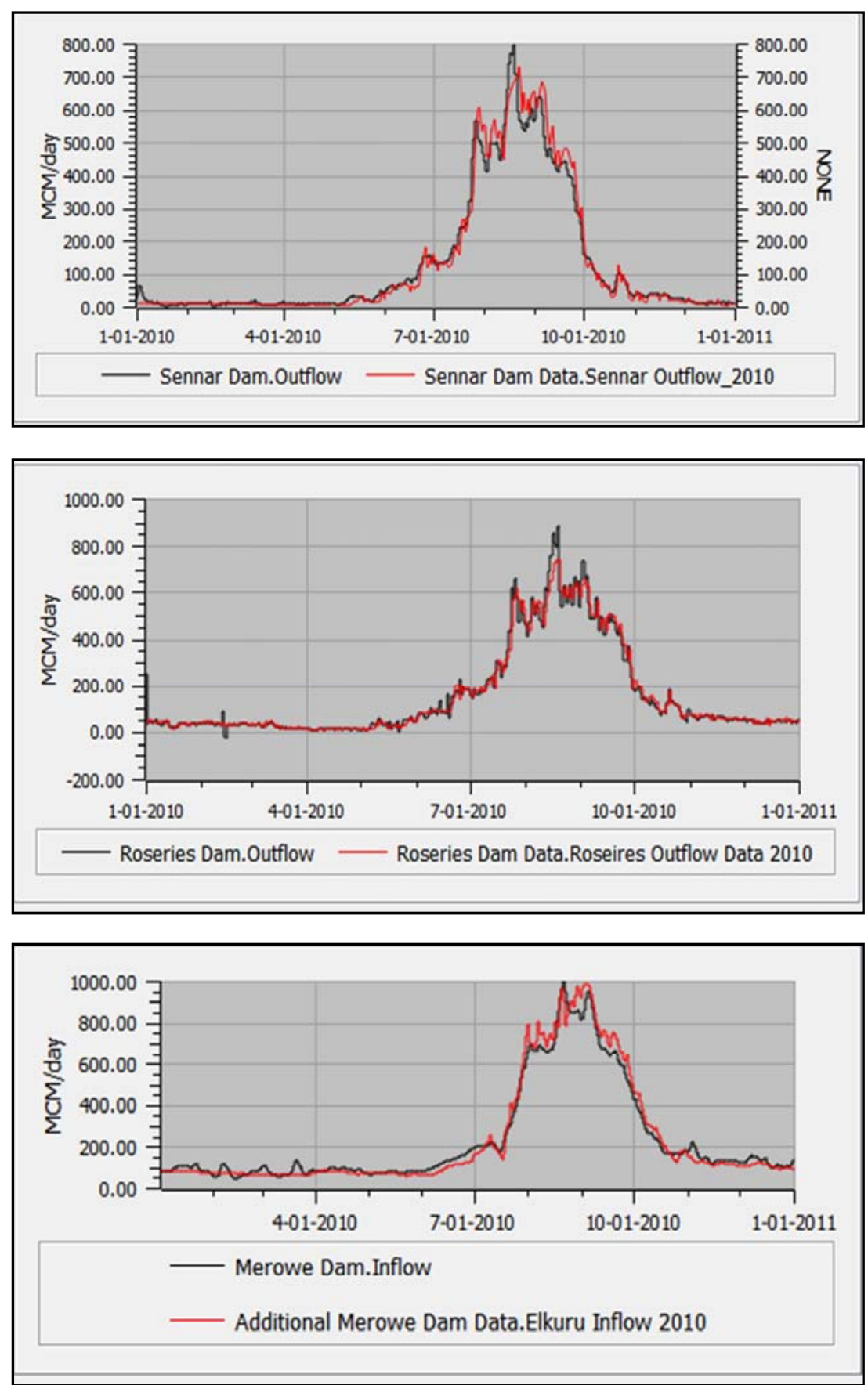

Figure 5. Model Calibration results (Simulated vs Observed).

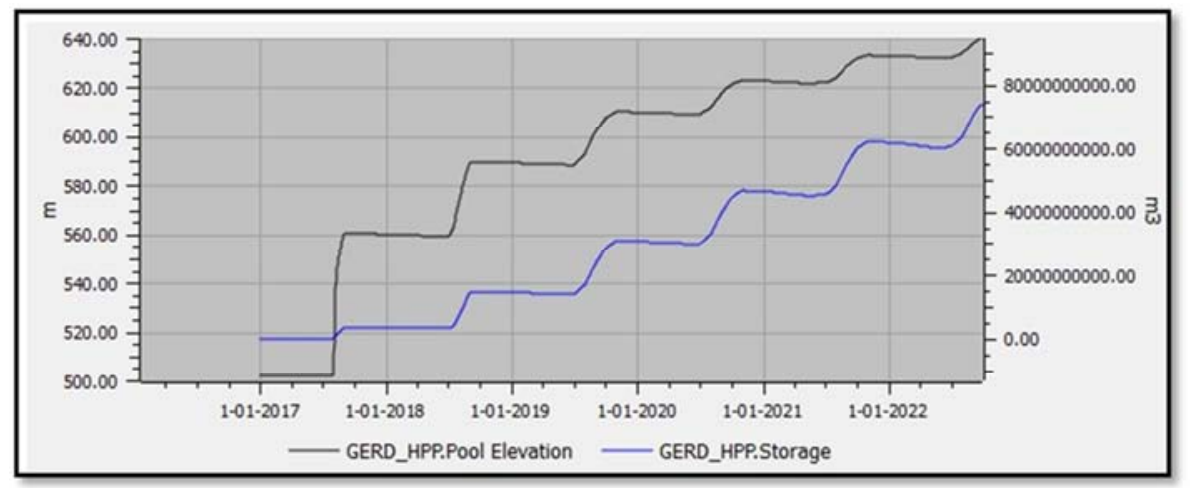




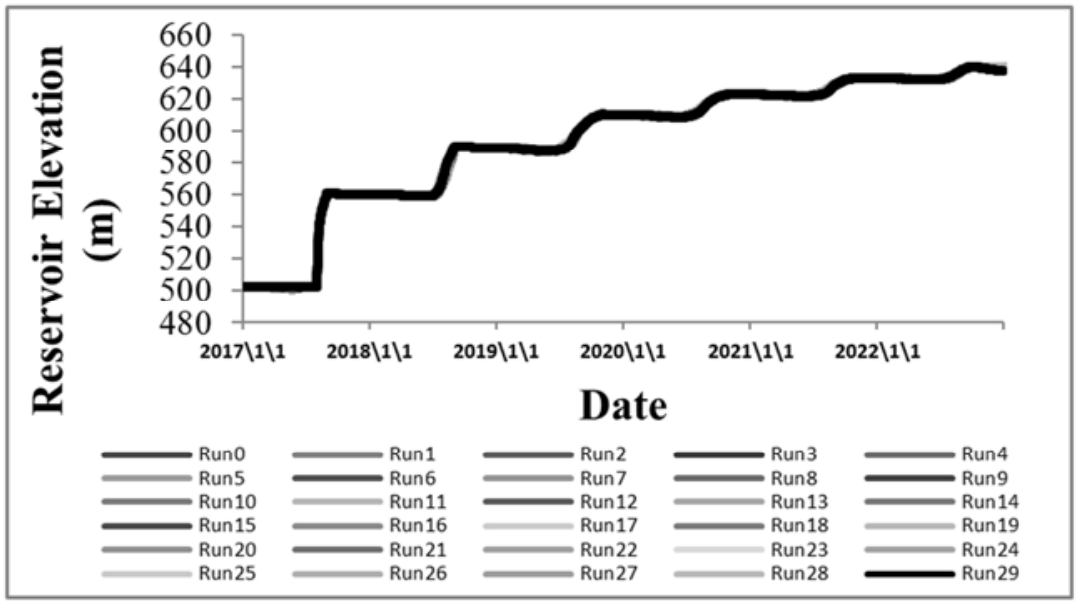

Figure 6. GERD First Filling Proposed Scenario for Elevation and Storage.

\subsection{Simulation of Long Term GERD Operation}

Generally, GERD is intended to be operated as proposed by Tractbel [3] as presented below:

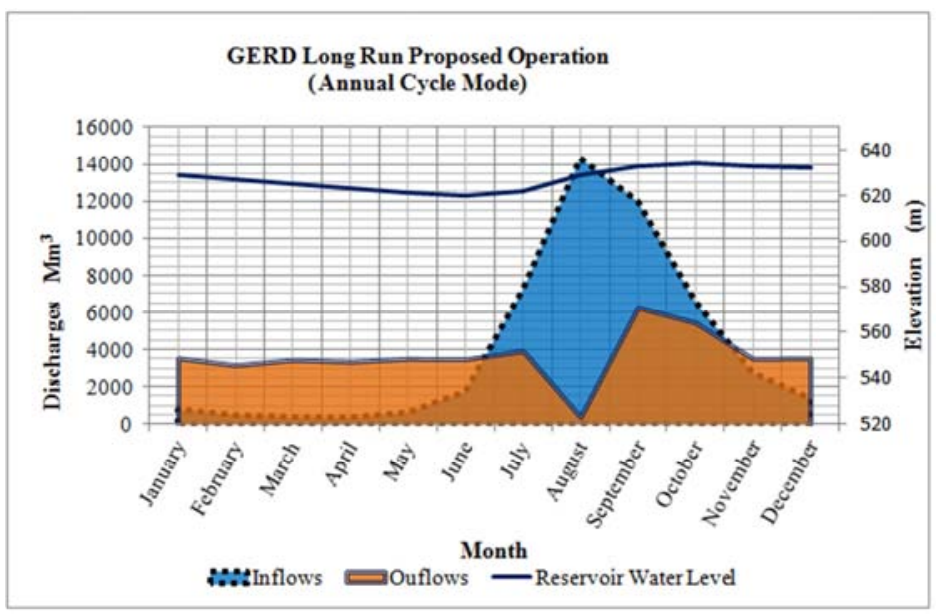

Figure 7. Proposed Long Run Annual Operation For GERD.

The mean monthly outflows from GERDP were taken as input inflow to Roseires dam and then routed to downstream (Figure 6).

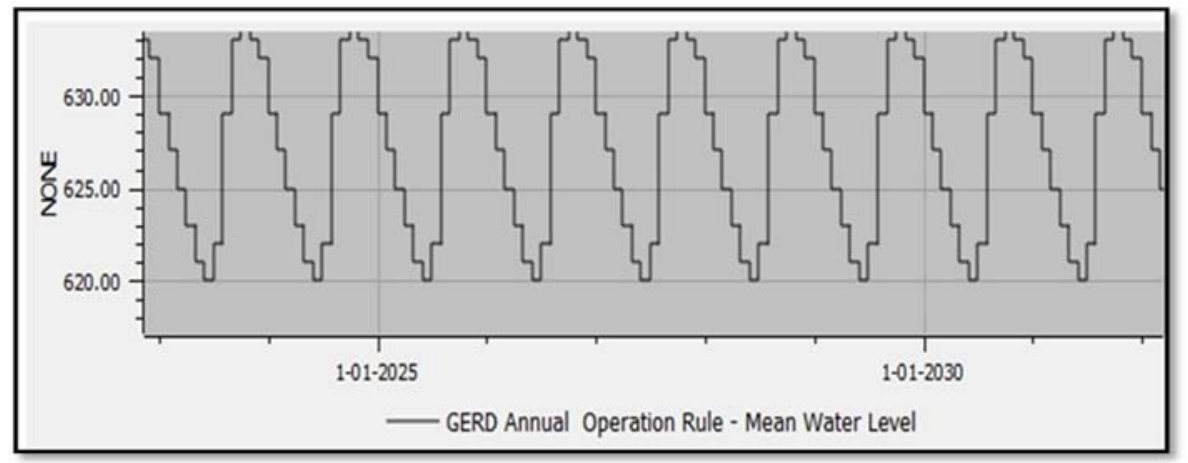

Figure 8. GERD Operation Guide Curve.

\section{Results and Discussion}

Generally, it's concluded that the model outputs are two sets of results, one representing the first impounding period which has been proposed to last in six years starting from 2018 up to 2023 with 30 Index sequential traces. In addition to the other period which considered to start after the GERD reservoir is 
completely filled and GERD is fully operational from 2023 up to the year 2046 with deterministic hydrology inputs.

\subsection{Results for First Filling Impacts}

In order to estimate the impact range of the first filling of the GERD on both Blue and Main Nile, the RiverWare simulation model had been run 30 times using one sets of data for 6 years in each run. The following results were obtained which explain the differences in certain parameters. These parameters are water levels, inflows, runoff and hydrograph shapes for six stations resembling the main reaches of the system. The stations represent different reaches which extend from Blue Nile areas down to the Main Nile ones, within Sudan territories. Results have been extracted from the model simulation during the first filling period runs, and consequently compared to the average base line case without GERD.

\subsubsection{Water Levels Impacts}

The differences in Water Levels are expected to varying from approximately 0 to $-3(\mathrm{~m})$ during first filling for all reaches throughout the year. No expected changes during summer times (Jan - June) for average and wet years. while a drop of approximately $1.0 \mathrm{~m}$ in all reaches is highly expected during dry hydrological years during summer times. Flood season (July - Sep) will be affected with drastic changes in water level by 1 to $3 \mathrm{~m}$ less than the average baseline especially for average and dry hydrological years (Figure 7).

\subsubsection{Inflows and Run-Off Impacts}

The differences in inflows and run-offs are varying from approximately 0 to $-41(\%)$ during first filling as an average for the expected impacts in Inflows rates and Run-Off either. For low flow season and dry years hydrology, it's observed that in some days the inflow rates are reduced by $90 \%$ less than the minimum baseline for the same dates (Figure 8).

the percentage of monthly differences envelope in Inflow rates and runoff parameters for the first filling period ranged with minimum, maximum and average.

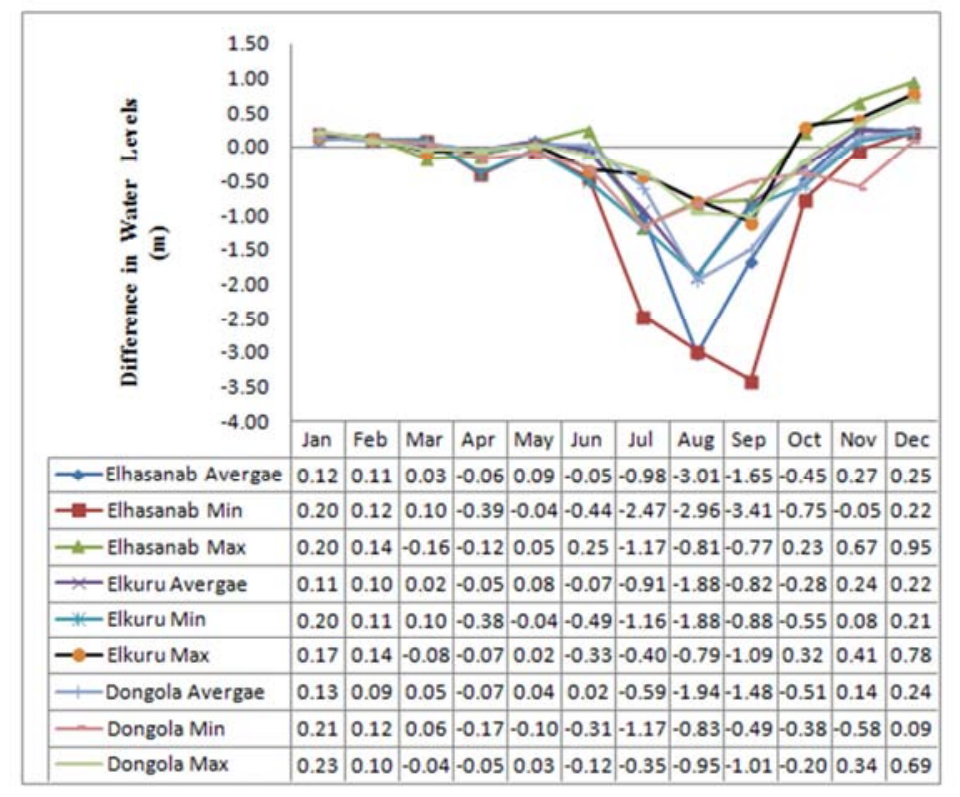

Figure 9. GERD Impacts on Water level for Sudan River Reaches during first filling.

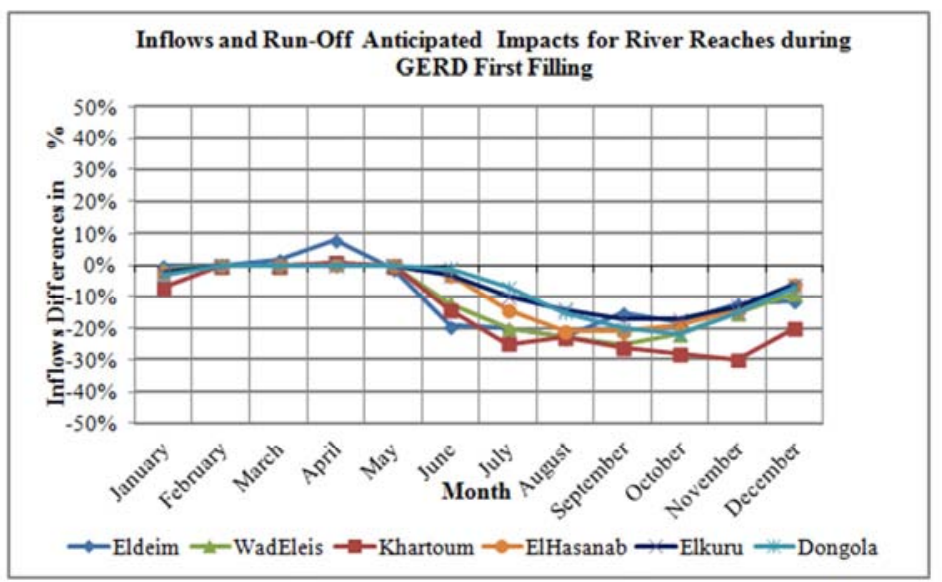

Figure 10. GERD Impact on Inflows and Run-offs for Sudan River Reaches during first filling. 


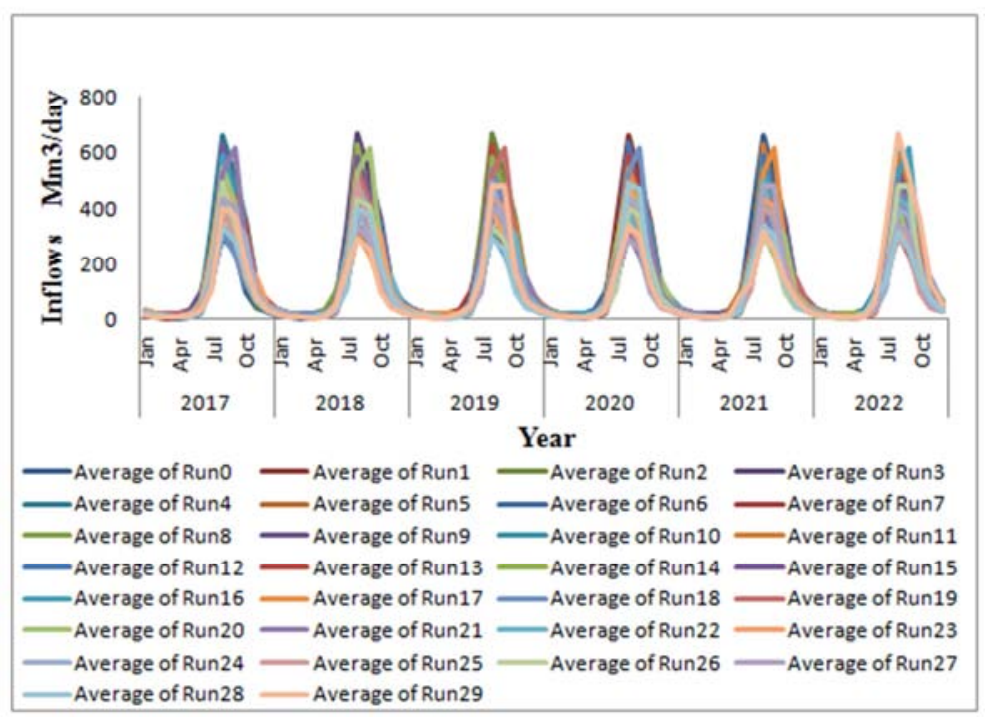

b

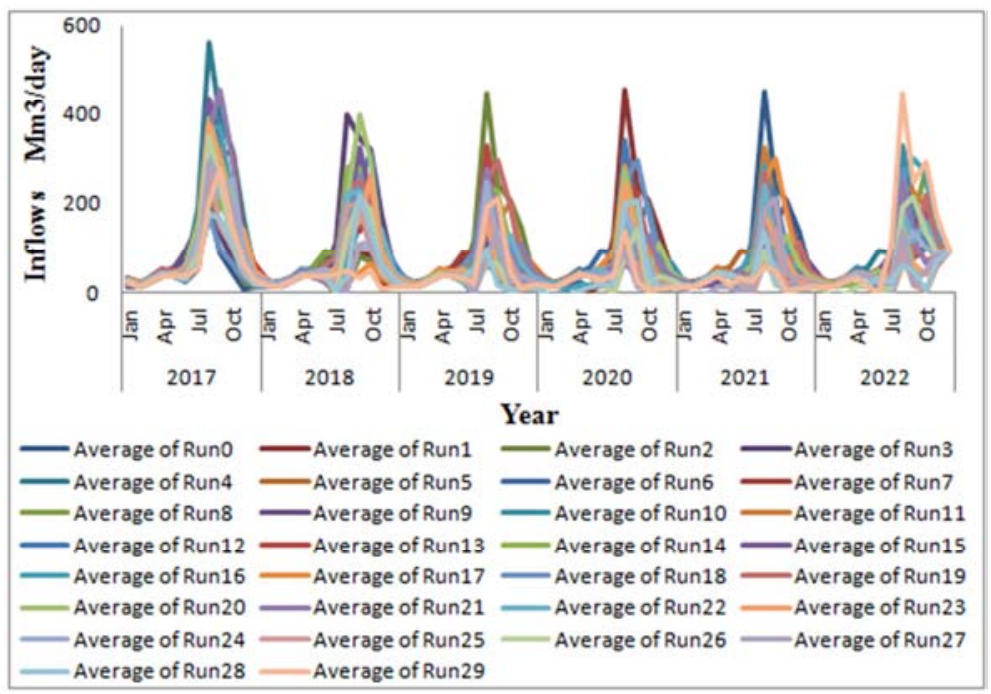

c

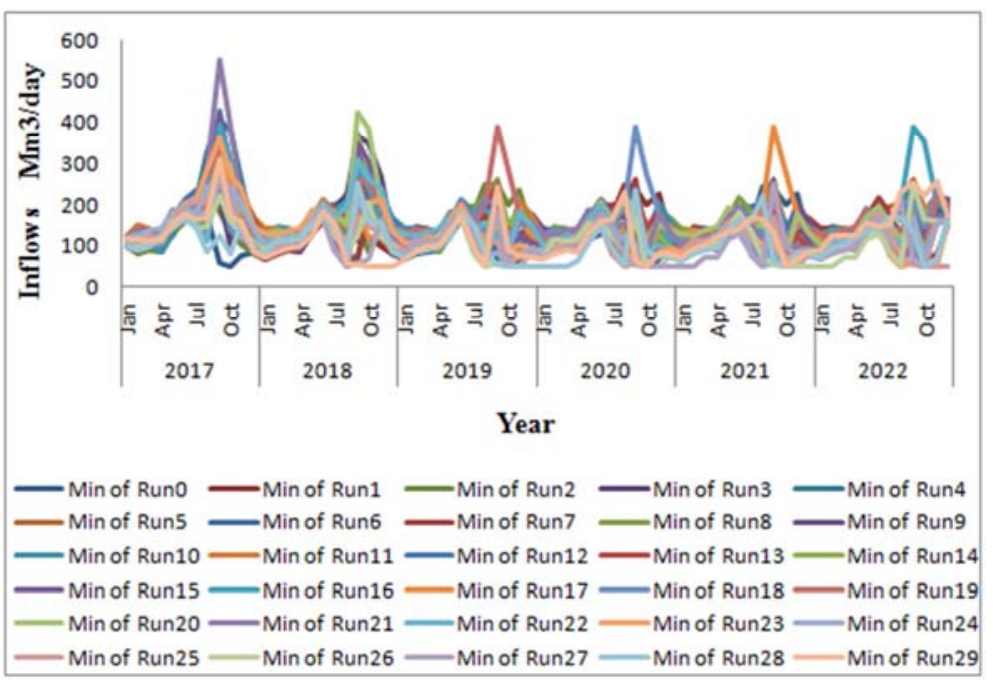

Figure 11. GERD Impacts on Inflow Hydrograph shapes during first filling for some Sudan River Reaches at : a) Eldeim station, b) Khartoum Station, and c) Elkuru Station. 


\subsubsection{Hydrograph Shapes}

It should be noted that, according to the filling assumptions, the peak discharges will be reduced by $15-30 \%$ while the inflow rates during summer time will remain same as baseline for $95 \%$ of the times. (Figure 9a) Shows the differences in hydrograph shape for Eldeim station before and after GERD during the first filling, (Figure 9b) shows these differences for Khartoum station and (Figure 9c) explains the differences during the first filling in inflow hydrograph for Elkuru station before and after GERD.

\subsection{Long Run Results}

To quantify the impacts of GERD on the long-run operation, same procedures were applied as before using two different sets of data for 42 years $(1969$ - 2010). Thus, the total time elapsed for simulation is 30 years which starts in 2017 and ends by 2046.

\subsubsection{Water Levels Impacts}

River-ware model results concluded that the impacts in Water Levels are expected to varying from approximately +2.17 to $2.30(\mathrm{~m})$ for the long run operation (2023-2064). (Figure 12)

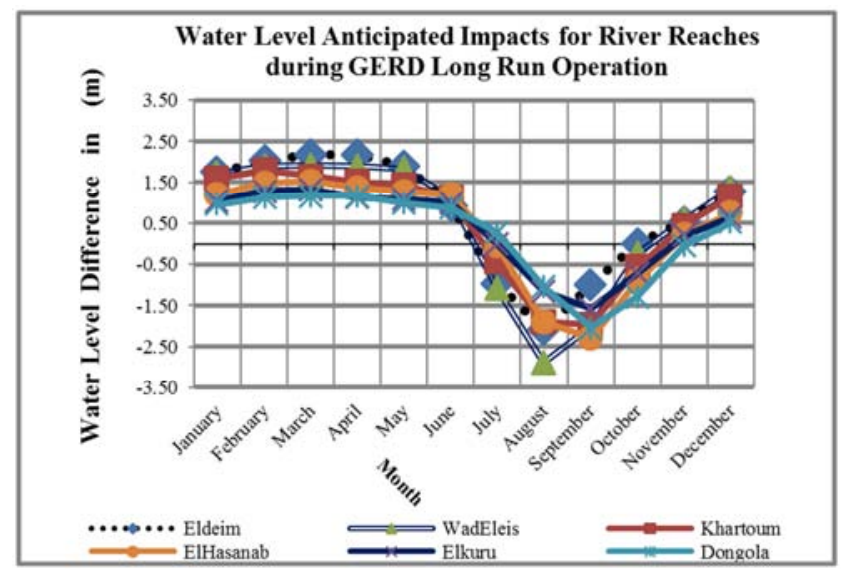

Figure 12. GERD impacts on water level for Sudan river reaches for long run.

\subsubsection{Inflows}

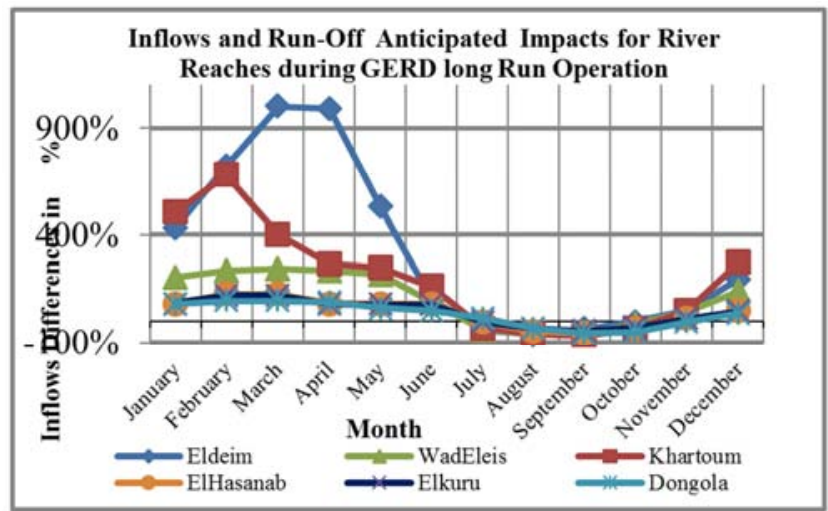

Figure 13. GERD impacts on inflows and run-offs for Sudan River reaches in long run operation.
The impacts in both Inflow rates and Run-Off volumes are expected to increase by a range from one to ten times for the long run operation. (Figure 11) explains the average percent differences in inflows for the period 2023 to 2064.

\subsubsection{Inflow - Duration Curves}

It's highly expected that, the inflows with probability of exceedance of $25 \%$ or higher to increase by 10 to $100 \mathrm{Mm}^{3} /$ day, while probability for daily inflow rates of $250 \mathrm{Mm}^{3} /$ day and above will be reduced by approximately $5-15 \%$. More specifically, we can see that, high flood peaks have less chances to occur and flood magnitudes will be $100-250 \mathrm{Mm}^{3} /$ day less than the normal average. (Figure 14a) explains the difference in discharge-duration curve for Eldeim station representing Blue Nile, while (Figure 14b) explains this difference for Elkuru station Which is representing the main Nile.
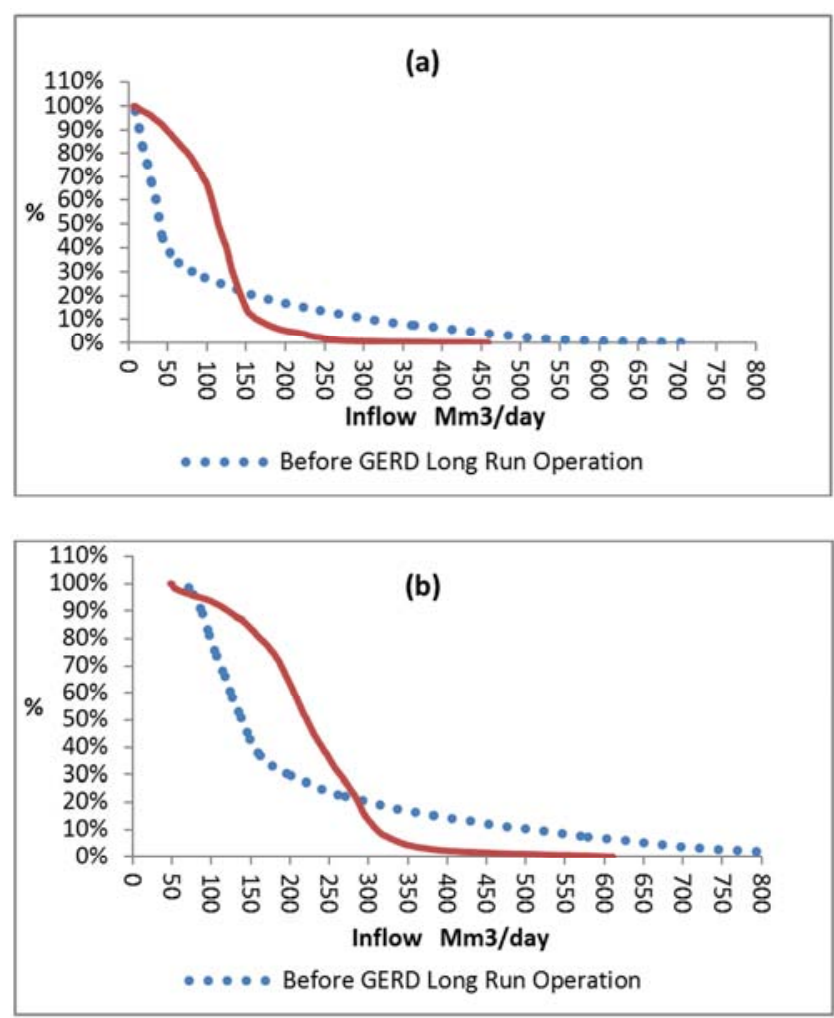

Figure 14. GERD Impacts on Discharge-Duration curve for Sudan river reaches for long run operation at : a) Sinnar to Khartoum, and b) Atbara to Elkuru Reach.

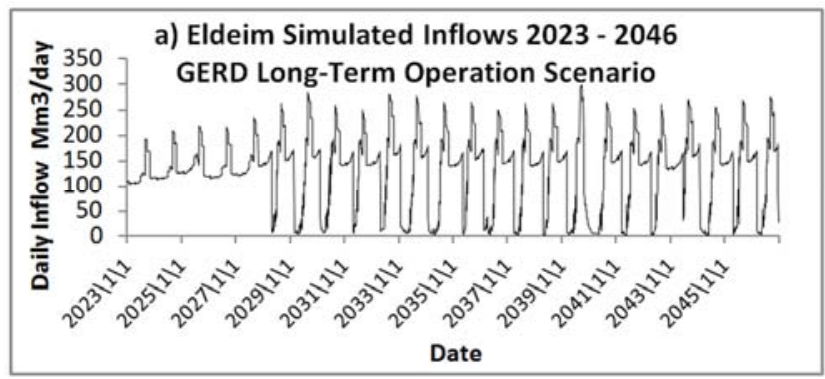



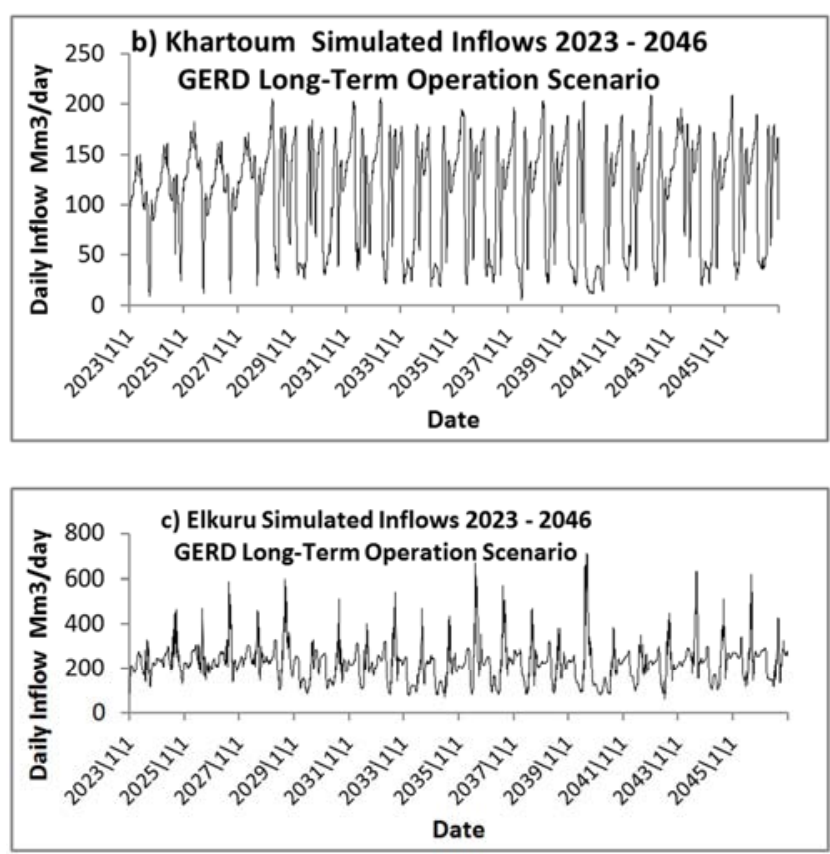

Figure 15. Simulated Inflow hydrograph shapes for Sudan River Reaches for long term operation at : a) Eldeim Station, b) Khartoum Station, and c) Elkuru Station.

\subsubsection{Hydrograph Shape}

It should be noted that, the peak discharges will be reduced by $50-250 \mathrm{Mm}^{3} /$ day while the daily inflow rates during summer time will be increased by $50-200 \mathrm{Mm}^{3} /$ day for all reaches. (Figure 15a), (Figure 15b) and (Figure 15c) explain the differences in hydrograph for Eldeim station, Khartoum station and Elkuru station respectively, Which representing the whole Sudan river reaches.

\section{Conclusion and Recommendations}

\subsection{First Filling Impacts}

As a conclusion, it is assumed to fill GERD reservoir within 6 years starting in 2018 to 2023 , and to retain $74 \mathrm{Km}^{3}$ of water for the first impounding. Water supposed to be stored only during flood season (July to October).

It could be stated that during the first filling, there are no significant impacts regarding water levels changes during summer times from January to June, for all reaches for both the wet and average hydrological years. While slight to moderate to severe impacts, between 0 to $-3 \mathrm{~m}$, may occur, specifically during July, August, September and October.

The main consequences are the reduction in inflow rates and run-off by ( 0 to -41$) \%$ from the average normal condition,

Furthermore, the hydrograph shape will remain as the same during summer times, on the other hand the peak will be reduced by $15-40 \%$. In addition to that, flood season will yield less water by $20 \%$ approximately.

\subsection{Long Run Operation Impacts}

Regarding long run operation, drastic changes are going to occur, and definitely, will affect all the Blue and Main Nile reaches concerning water level, inflow rates, runoff and hydrograph shape.

In depth analysis for the long run results indicates that there will be significant changes during summer times and it's highly expected the water level will rise in all Blue and Main Nile reaches up to $2.5 \mathrm{~m}$ higher than normal, while draw down in water levels is expected during flood season by $2-3 \mathrm{~m}$.

Accordingly, the flow rates will increase during summer 5 to 10 times and flows during the flood period will be reduced by approximately $-67 \%$ compared to the average mean before GERD.

Furthermore, the hydrograph will severely changed. The parabolic shape for the summer hydrograph will tend to be flat line lifted up, while the peak, most likely, will be flattened and attenuated by 30 to $60 \%$ for different years.

For long run, it's highly expected the inflows with probability of exceedance of $25 \%$ or higher will increase by 10 to $100 \mathrm{Mm}^{3} /$ day, while probability for daily inflow rates of $250 \mathrm{Mm}^{3} /$ day and above will be reduced by $5-15 \%$ approximately. It should be noted that, high flood peaks have less chances to occur and flood magnitudes will be $100-250$ $\mathrm{Mm}^{3} /$ day less than the normal average.

Flood annual peak will be reduced by $50-250 \mathrm{Mm}^{3} /$ day, while the daily inflow rates during summer periods will increase by $50-200 \mathrm{Mm}^{3} /$ day for all reaches.

In general, the imposed impacts of GERD on Nile Hydrology are serious issue, which should be taken into consideration, sine the changes might be in both ways, negative and positive.

It's recommended to prepare and implement action plan to eliminate and mitigate, as possible, the anticipated impacts and highlight the opportunities to get benefits from the prospective chances of water availability in different fields with new scopes and creative approaches.

\section{References}

[1] Ministry of Water Resources and Electricity, Ethiopia (May, 2013), "International Panel of Experts Report on GERD," Addis Ababa, Ethiopia.

[2] Merowe Dam Electricity Company (MDEC) (2013), "Rosaires Efect on Merowe Dam Generation," Merowe, Sudan.

[3] André Alberto Weber (2013), et al, "Downstream impacts of a dam and influence of a tributary on the reproductive success of Leporinus reinhardti," AQUATIC BIOLOGY, pp. Vol. 19: 195-200, 2013. Retrieved March 2018.

[4] G. P. Williams, and M. G. Wolman (1984), "Downstream effects of dams on alluvial rivers," United States Geological Survey Professional Paper 1286, Washington, DC: US Government Printing Office.

[5] Paweł Marcinkowski and Mateusz Grygoruk (2017), "LongTerm Downstream Effects of a Dam on a Lowland River Flow Regime: Case Study of the Upper Narew," Water, vol. Adaptive Catchment Management and Reservoir Operation. 
[6] Alan Nicol, Mamdouh Shahin (2003), "The Nile: moving beyond cooperation," UNESCO, PCCP.

[7] Claudia Kuenzer, et al. (2012), "Understanding the impact of hydropower developments in the context of upstreamdownstream relations in the Mekong river basin," Sustainability Science.

[8] Lu X, Wang J, Grundy-Warr (2008), "Are the Chinese dams to be blamed for the lower water levels in the lower Mekong? In: Kummu M, Keskinen M, Vairs O (eds) Modern myths of the Mekong," Water \& Development Publications, p. 39-54.

[9] Chapman EC, He D (1996), "Downstream implications of Chinas dams on the Lancang Jiang (Upper Mekong) and their potential significance for greater regional cooperation," Sydney, Australia.
[10] Shokhrukh-Mirzo Jalilov (2010), "IMPACT OF ROGUN DAM ON DOWNSTREAM UZBEKISTAN AGRICULTURE," Fargo, North Dakota.

[11] T. E. COYNE ET BELLEIR (2011), "Grand Ethiopian Renaissance Dam Project Impounding and Operation Simulations Impact Study on High Aswan Dam," HYDROLOGICAL AND RESERVOIR SIMULATION STUDIES, Addis Ababa, Ethiopia.

[12] (March 2017), [Online]. Retrieved from RiverWare Website: http://wre.gov.sd/hrc/index.php/portfolio/project-1.

[13] (May 2017) "World Atlas," [Online], Retrieved from Infographic (C) Codi Yeager-Kozacek / Circle of Blue.

[14] (January 2017), [Online]. Retrieved from RiverWare Website: http://cadswes.colorado.edu/creative-works/riverware. 